DISCUSIONES

\title{
CONSCIOUS MIND AND UNCONSCIOUS INFERENCE: HUGO MARGAIN'S \\ RATIONALITY, LANGUAGE AND PHILOSOPHY
}

\author{
MARK PLATTS \\ Birbeck College, London, \\ e Instituto de Investigaciones \\ Filosóficas
}

§1 Hugo Margåin Charles had been Director of the Institute of Philosophical Research in the National Autonomous University of Mexico for just five months when he was murdered during an attempted kidnapping within the University. Although only thirty five at the time of his death, he was clearly the outstanding exponent and practitioner of analytical philosophy within the Spanish-speaking world. He was just completing work on the final proofs of Racionalidad, Lenguaje y Filosofía (Fondo de Cultura Económica, 1978), a collection of some of his papers, nearly all published elsewhere. In discussing some of the central themes of this book, the temptation to eulogise was close to overwhelming; but I have tried to write in the uncompromisingly critical spirit its author would have wanted.

\section{\$2 Materialism and the Language of Mind}

The first three papers in this book are concerned with some of the central problems arising from our employment of mentalistic language. Two particular problems unite the otherwise disparate concerns of these papers. How, if at all, can our reliance upon mentalistic language in describing human beings be reconciled with a materialistic view of those same beings, the view that such beings are composed solely of the stuff which the material sciences investigate? And how, if at all, can defensible use be made within such mentalistic talk of notions of unconscious mental states?

In the first two papers Margáin tries both to show that these are substantial and complex problems, and to show 
why the standard Cartesian framework - with its decisive negative responses to each of our questions - must be rejected. But it is the third paper, 'Freud, Mentalism, and Materialism', which both promises and delivers a far more substantial contribution.

Throughout his life Freud was some kind of materialist. Even after his abandonment of the early project for an explicitly neurophysiological psychology - that project having seemed to him the only alternative to a Cartesian conception of the mind which would preclude its scientific study - he continued to think of the subjects of his study, people, as (complex) material beings. (The origin of his theory of the interpretation of dreams is instructive here.) So our first problem, that of justifying talk of a material being in mentalistic terms, can be raised in connection with each stage of Freud's development.

Whatever solution is given to that problem of Freudian justification, it remains clear that, for Freud, his materialism was not just a chance companion of his other mature theories about psychological science. Given the fragmentary nature of conscious mental life, Freud saw no hope for a science of the mind which treated only of conscious mental states. Attribution of unconscious mental states is needed to fill out the gappy stream of consciousness, much as the positing of persisting objects - persisting even when unobserved - is needed to fill out the fragmentary sequences of actual observations of objects if a scientific theory embracing those objects is to be possible. Thus Freud was led to our second question, about the defensibility of talk of unconscious mental states; and from there he was led to materialism. For Freud, defence of the use of notions of unconscious mental states required materialism. (This same line of thought may explain Chomsky's attachment to materialism since many of the mental, including innate, states Chomsky wishes to posit are unconscious; see, for example, the quotation from Chomsky at p. 12 of Margáin's book.) Consciousness is held to be just an extra quality which some neurophysiological proces- 
ses have. (Thomas Nagel's 'Freud's Anthropomorphism', which prompted Margáin's paper, is good on the ambiguities here.) The justification for talk of unconscious mental states is that their neurophysiological foundations are structurally similar to those of the corresponding conscious mental states. For Freud, as for Chomsky, the relevant neurophysiological findings - indeed, the relevant neurophysiological terminology - may be a long way off; but the belief that the facts are there to be discovered is our only defence of talk of the unconscious, talk essential if there is to be a scientific psychology.

Freud says, for example, that "if ... we say "At this point an unconscious memory intervened", what this means is: "At this point something occurred of which we are totally unable to form a conception, but which, if it had entered our consciousness, could only have been described in such and such a way"'. Nagel, having explored the limitations of Freud's analogy with visualisation (imagining) of unobserved processes in the physical sciences, convincingly argues that 'if we believe the hypothetical proposition, it is because we believe something else: namely that there is a similarity in structure between the invisible thing we are talking about [e.g. the unconscious memory] and other, visible things that look a certain way [e.g. conscious memories]; and that this structural feature is responsible for their looking that way'. For Freud, these underlying structural features will be described in the language of some future neurophysiology.

Such reference to (present or future) neurophysiology cannot work for Freud any more than it can for Chomsky, for reasons essentially those given by Margáin in his discussion of Chomsky, Brentano, and Davidson. We understand too well the autonomy, in terms of point, of mental discourse to expect the requisite psychophysical laws explaining phenomenological features however long we wait.

How, then, can the talk of unconscious mental states be defended? All that is needed, Nagel suggests, is the belief in 'the possibility of an independent characterization of [e.g.] 
the unconscious process'. We cannot expect such a characterization of any relevance from any neurophysiological theory, however distant and however different; and so, Nagel seems to suggest, we must wait upon some future psychological theory of a non-neurophysiological kind to produce the necessary independent structural characterization. Such a theory will presumably be neutral as regards all forms of materialism.

Nobody could rule out a possibility described in such terms; but is is difficult to see a philosophical solution in Nagel's remarks. Margáin prefers to look for errors in the way of framing the problem - errors deeply (and historically unsurprisingly) rooted in Freud's thought, and which have been, perhaps, unwittingly transmitted to Nagel.

Freud's general philosophical position seems to have been founded upon one way of construing Kant's transcendental idealism, and it is this, Margáin thinks, which leads to the difficulties we have just examined. This neo-Kantian position has two main components: the first is the thesis that "things in themselves" are unknowable since we can never free ourselves from the forms imposed upon our experience of the world by the faculties of our mind; the second is the thesis, operative even within the restrictions imposed by the first, that any theoretical terms used in our description of our world must, to have defensible content, be reducible to theoryfree observational terms. Given this position, Freud's specific problems about the conceptual foundations of psychological science arise immediately if a further thesis is attributed to him: that in the language of psychology the theory-free observational terms are those for conscious mental states where such terms are to be defined by reference to the phenomenological (introspectible) content of the corresponding mental states.

I have spelt out this network of views somewhat more deliberately than does Margáin; but I think it clear that he rejects each component of the network, and I also think it 
clear that he is right to do so. But what, then, are his answers to our two questions?

We ascribe mental states to (material) agents in order to understand those agents, in order to make sense of them and their doings. Such explanations are in principle irreducible to, and in fact often better than, any explanation offered in material terms. That, briefly, is Margáin's answer to the first question about the possibility of mentalistic descriptions of material beings. The meanings of such mentalistic descriptions are not given through any connections with "phenomenological facts". There is thus no general problem of the kind envisaged by Freud and Nagel, about the content, the meaningfulness, of talk of unconscious mental states, states without phenomenological content. Content is given to such talk, as to all mental talk, by its role within explanatory theories, theories which enable us to make sense of people and their behaviour. That seems to be the core of Margáin's answer to the second of our questions, an answer which leaves us free to decide general issues about materialism on other grounds.

As a diagnosis of one pseudo-genesis of a problem all that seems admirable. But two doubts arise. The less important is whether or not Margáin correctly characterizes the philosophical views tacit in Freud. Once we clearly distinguish the two main components in the neo-Kantian position - the unknowability of "things in themselves" and the condition of reduction of theoretical to observational terms- it is unclear, at least on the basis of the texts Margáin and Nagel cite, that Freud subscribed to the second, reductivist component, at least in the way Margáin understands that component. The texts cited can at least as naturally be read as expressing the first neo-Kantian component. This is part of a familiar problem of interpreting transcendental idealist doctrines: essentially, that of knowing quite what counts, in Kantian terms, as the "phenomenal world", or, in Freudian terms, as the "language of our perceptions".

The other doubt is more serious. Even if the genesis of 
Freud's problems about mentalistic talk in general and talk of the unconscious in particular is indeed a pseudo-genesis, it does not follow that the problems so generated are pseudoproblems. Indeed, it seems that these problems must live on within Margáin's own account.

Margáin tells us very little about the existence, nature and role of phenomenological facts, except the negative points presumed to be established by the private language argument. And he tells us virtually nothing of a non-negative character about the nature of, or the notion of, consciousness. In consequence he ignores the possibility that this notion is intimately connected with the intentionality of mental states, and so with the irreducibility of mental to material explanations. He tells us that ' $a$ is in pain' has the same meaning in the mouth of $a$ as in the mouth of others since the utterance will have the same truth-conditions in either kind of case (p. 23), even if $a$ and the others 'find themselves in a different epistemological relation with respect to $a$ 's pain' ( $p$. 21 ). But he elaborates neither upon the distinctive kind of 'epistemological relation' $a$ stands in to $a$ 's pain nor upon the (problematic) realism about mental states which comes with this separation of truth-conditions and evidence. Nor does he explore the differences between $a$ 's saying ' $a$ is in pain' and $a$ 's saying 'I am in pain', differences which connect with a difference of point of view which can help to illuminate the notion of consciousness.

Given these omissions, it seems either that Margáin's account is woefully incomplete, ignoring too many problems, or that it is simply implausible, allowing no special role to the notion of consciousness in fixing our understanding of the idea of the mental life. Too many doubts and possibilities are ignored in his discussion rather than being silenced or eliminated.

\section{$\S 3 \quad$ Logics and Languages}

The beautiful little essay 'Validity, Inference and Implica- 
tures' begins, as does the preceding note 'A Paradox', from some confusions which would be staggering had they not emanated from the work of Bunge. Fortunately this ethereal ladder is quickly glanced away as Margáin sets out to distinguish various kinds of problems about the natures of, and relations between, formal logical languages and natural languages.

The first set of problems arises within the study of formal logical languages, and can be resolved within that study. The syntactical structures and semantic properties of these languages can be stipulated with a precision which permits rigorous definition for such languages of notions like logical validity and logical consequence. (That is not to say that there cannot be substantive disputes about proffered definitions; it is just to acknowledge a distinctive kind of problem.)

What can produce at least the appearance of distinct substantive philosophical difficulties are questions about the relations between such formal languages and everyday natural languages. On the one hand, formal languages are often developed with an eye to illuminating our usual thoughts about our usual languages — for example, our thoughts about valid argumentation within natural languages. But on the other hand, a reasonable methodology requires that development of formal languages exhibit a certain disregard for their connections with natural languages. The apparent tension here too readily invites the illusory thought that there are two quite unconnected disciplines here; but the failure to notice the appearance of tension can be just as blinding (as in Bunge's denial of the validity of the inference from $P$ to $P v Q)$.

Margáin skilfully avoids the pitfalls here. Within a formal system notions like logical validity receive exact definition; but study within such a system places aside other problems, most notably 'the problem of the logical form of natural languages and the problem of how the relation of reference between a linguistic entity and an object can be given' ( $p$. 82). To say that 'mathematical logic is concerned with ar- 
tificial languages is a confused way of saying that mathematical logic is not concerned with the application of its theories to natural languages' (p. 82).

We are thus led to the second kind of problem: that of determining whether a specified formal language can be taken to represent, via appropriate transformational rules, the structure of a given natural language. Here Margáin tries to sidestep the familiar Quine-Strawson disputes by invoking Grice's work upon conversational implicatures; he suggests that once we employ Grice's sophisticated apparatus at least most of the (standard) differences between English (or Spanish) and first-order logical languages are revealed as illusory. Such logical languages are therefore still plausible candidates for representation of the 'logical grammar' of English (or Spanish); we can thus unproblematically carry over our definitions of logical validity and logical consequence to these natural languages.

Margáin explains all this in a brief but admirably lucid way. The final kind of problem he distinguishes is that of the relations between logically valid argument forms and inference, where the latter is understood as 'the rational process by which a person changes his beliefs, be it by acquiring new beliefs, rejecting others that he used to hold, or modifying them' (p. 94). Margáin's main thesis here is that the specification of logically valid argument forms has nothing to do with our understanding of inference since a (rational) inference is never constituted just by a logically valid argument.

This thesis, expounded in other ways by Gilbert Harman, is defended by Margáin by means of an imaginative employment of Lewis Carroll's parable of Achilles and the Tortoise. That familiar story, according to Margáin, shows as incorrect the idea that 'an inference can be composed of a valid argument' (p. 97) ; this is because the story shows that 'the complete description of a valid deduction does not include all the elements which make rationally necessary or possible acceptance of the conclusion' (p. 98). The need for further 
premisses (without limit) to force or "deductively justify" Achilles' inference does not show the original argument to be invalid, nor does it show that Achilles cannot obtain the conclusion of the valid argument through application of rules of derivation. Rather, what it shows is that our understanding and assessment of inference cannot be accounted for by the theory of logically valid argumentation. Even when we have solved the first two kinds of problems that of constructing a theory of rational inference will remain.

It is at this point, when Margáin presents a positive theory about the nature of inference, that my gravest doubts begin; for it is here that Margáin takes over another thesis of Harman's, that of the holistic character of inference. The idea is that the "premisses" of an inference "are all the beliefs of the reasoner prior to the inference', and that its "conclusion" is "the modified totality of beliefs which result from the inference' (p. 104). Margáin's argument for this thesis is that "whenever we are offered an inference described in "partialist" [i.e. non-holistic] terms we can imagine a belief, outside of the premisses described, such that if the reasoner held it, the inference would cease to be rational' (p. 108).

Margáin also holds, I think, the distinct thesis that all beliefs are the result of inference. He says that "we should assert that there is an inference... when there is more than one possibility of interpretation, even if the choice between diverse possibilities is not made consciously, even if the decision is automatic' (p. 109). So, for example, 'if the statements of mathematicians are $a$ posteriori, that is, grounded in experience, even if indirectly, then their acceptance is the result of a complex inference in which account is taken of their explanatory value within our general theory of the world' (p. 109). Since Margáin's book is pervaded by a scepticism about the $a$ priori, it seems fair to conclude that, for him, each belief held is the result of an inference. Nearly all such inferences will be unconscious; all will be correctly described only in holistic terms.

My first doubt here, put at its briefest, is this. The argu- 
ment for holism, like that for the all-pervasiveness of inference, seems to me to rest upon a lingering scepticism which (for good reason) fits ill with the general tone of Margäin's work. In the Philosophical Investigations, Wittgenstein's interlocutor says at one point: 'But, if you are certain, isn't it that you are shutting your eyes in face of doubt?' Wittgenstein replies: 'They are shut' (p. 224). The point of this reply, I take it, is to distinguish between our eyes being shut to doubt and our shutting our eyes to doubt.

It is a fact of our nature that our eyes are shut to doubt. That our eyes are shut does not constitute a further belief of ours; it is just a fact of our natural history. There could be creatures whose eyes were always open to doubt, and there could be creatures who shut their eyes having seen, and admitted, the doubt. The latter would be well described by the Harman-Margáin thesis; but we are not. Given that, the ever-present possibility of doubt - of alternative total belief sets, of alternative interpretations- is no reason to describe our inferences using either the holistic thesis or that of the all-pervasiveness of inference.

The other, closely connected, worry is about the free and easy play made by Margáin with the notion of inference. That play will lead Margáin to attribute to rational beings a grasp upon concepts which, in some cases, there is no reason to think that they have. An example: we see a certain array of black and white dots upon a card as a face. Is that an inference from some (unconscious) perception of the dotarrangement neutrally (say, geometrically) described? Our seeing the face may, of course, causally depend upon numerous factors which are reflected in other beliefs we have; and there are countless possibilities of diverse "interpretation". But how could the perception be an inference in the case of a person to whom the neutral, geometrical description would be quite unintelligible? Even when the person concerned has the necessary conceptual repertoire the problems are not over. To a creature who saw the face as a result of a conscious inference, how it seemed to be -at least the 
initial look of the card- would be utterly different from how it looks to us, even though we do have the necessary conceptual repertoire. What, then, is the rationale for employing the notion of an unconscious inference when, were that "inference" conscious, the very form of our perception would be radically different? Margáin's studied neglect of phenomenology makes it far too easy for him to acquiesce in an employment of talk of unconscious inferences which seems devoid of content.

\$4 Much else in Hugo Margáin's book merits detailed examination. There is an admirable discussion of the logic of existence statements, exhibiting a firm grasp upon the many complex issues which arise in that area. There are discussions of causality and explanation which serve, at the very least, to pose important questions in clear ways and to brush away much of the confusion which has come to pervade philosophical discussions of their subject matters. And the whole book reflects a profound and accurate understanding of the philosophy of Quine - especially of his programme of naturalized epistemology.

I have chosen to discuss just two of the central, connected themes in this rich book. I could not bring myself to write about the elegant and humane essay on violence and rationality. I still find it as difficult as it is painful to accept that I shall not now hear Hugo's answers to my objections: answers that I know would have been as honest, intelligent and engaging as the man himself. 